\title{
NOTICIAS
}

\section{Presencia de México en la XI Conferencia Mundial sobre Tabaco o Salud}

Se celebró, recientemente, la XI Conferencia Mundial sobre Tabaco o Salud $(\mathrm{WCTOH}$, por sus siglas en inglés) en la ciudad de Chicago, del 6 al 11 de agosto. Este evento, bajo el lema "Promover un futuro sin tabaco", estimuló el intercambio de ideas y de experiencias para desarrollar un consenso en la estrategia global de control y prevención del consumo de tabaco. Ese fue un marco propicio para que trabajaran conjuntamente las diferentes disciplinas de la salud y los líderes nacionales y comunitarios, así como para identificar nuevas vías y tecnologías que ayuden a erradicar la epidemia de tabaquismo.

Se pueden identificar tres temas centrales de esta reunión: el primero de ellos, referido a la revisión de Avances en la estrategia mundial de control del tabaco; el segundo, dedicado a Nicotina, presente y futuro y, por último, el tercero, denominado Acciones para defender a los no fumadores y promover los espacios sin humo. Con base en estos tópicos se establecieron las siguientes propuestas:

- fortalecer e incrementar el número de instituciones e individuos vinculados en la lucha contra el tabaco,
- promover ideas y estrategias que impulsen cambios sociales, políticos y económicos que ayuden a reducir el consumo en el ámbito mundial,

- mostrar la importancia que tiene fortalecer y comprender la necesidad de cambio de la política hacia el tabaco, y

- estimular la formación de redes de trabajo que compartan estas estrategias.

México presentó en esta reunión 24 trabajos, siendo el país latinoamericano más representado. Las ponencias mostraron los resultados obtenidos por el Grupo de Estudio del Tabaquismo del Instituto Nacional de Salud Pública, el Instituto Nacional de Enfermedades Respiratorias y de la Dirección General de Epidemiología, de la Secretaría de Salud.

La amplitud de temas presentados por México en la WCTOH se aprecia en la diversidad de espacios de discusión a que fueron invitados sus delegados. Los trabajos se expusieron en sesiones dedicadas a: a) las ciencias de la adicción; b) las aproximaciones culturales al control del tabaco; c) las políticas públicas; d) la industria del tabaco y nicotina; e) las tácticas y estrategias para influir en las actitudes y las políticas respecto al tabaco; f) la cesación y tratamiento de la dependencia; g) el control del tabaco y el medio am- biente, así como varias sesiones de carteles.

Los resultados presentados se refieren, fundamentalmente, a investigaciones en las áreas siguientes: uso de marcadores como la cotinina; estimaciones de prevalencia en grupos de riesgo, como son las mujeres y los adolescentes y jóvenes; factores económicos como determinantes del consumo. Asimismo, sobre experiencias en clínicas de tabaquismo y tratamientos para lograr la cesación, así como estudios clínicos relacionados con los efectos de la exposición al humo de tabaco en el ambiente; el cultivo de tabaco y uso de insecticidas, y el análisis del contenido de la publicidad de cigarros.

En el marco de la WCTOH se efectuó, con auspicio de la Organización Panamericana de la Salud, la conferencia Aproximaciones innovadoras en los estudios sobre tabaco en América Latina: hacia una mejor práctica, en la cual se presentaron experiencias de varias naciones, México entre ellas, y se fomentó la discusión e intercambio entre países de la región. Esta reunión incluyó una sesión de carteles en la cual se premiaron tres de los trabajos expuestos, de éstos, uno del Instituto Nacional de Salud Pública de México, presentado por la M. en C. Luisa María Sánchez Zamorano y colaboradores.

En la Conferencia Mundial se puso de manifiesto que entre los re- 
tos actuales que tiene que enfrentar la estrategia global de prevención y reducción del uso de tabaco está el vertiginoso incremento de la prevalencia de consumo que se ha observado en las últimas décadas en países como China, India y, en gene- ral, todo el sureste asiático, así como en muchos países africanos. En América Latina, como se muestra en la figura 1, las cifras también son preocupantes.

De acuerdo con lo anterior, se evidenció que mientras la industria

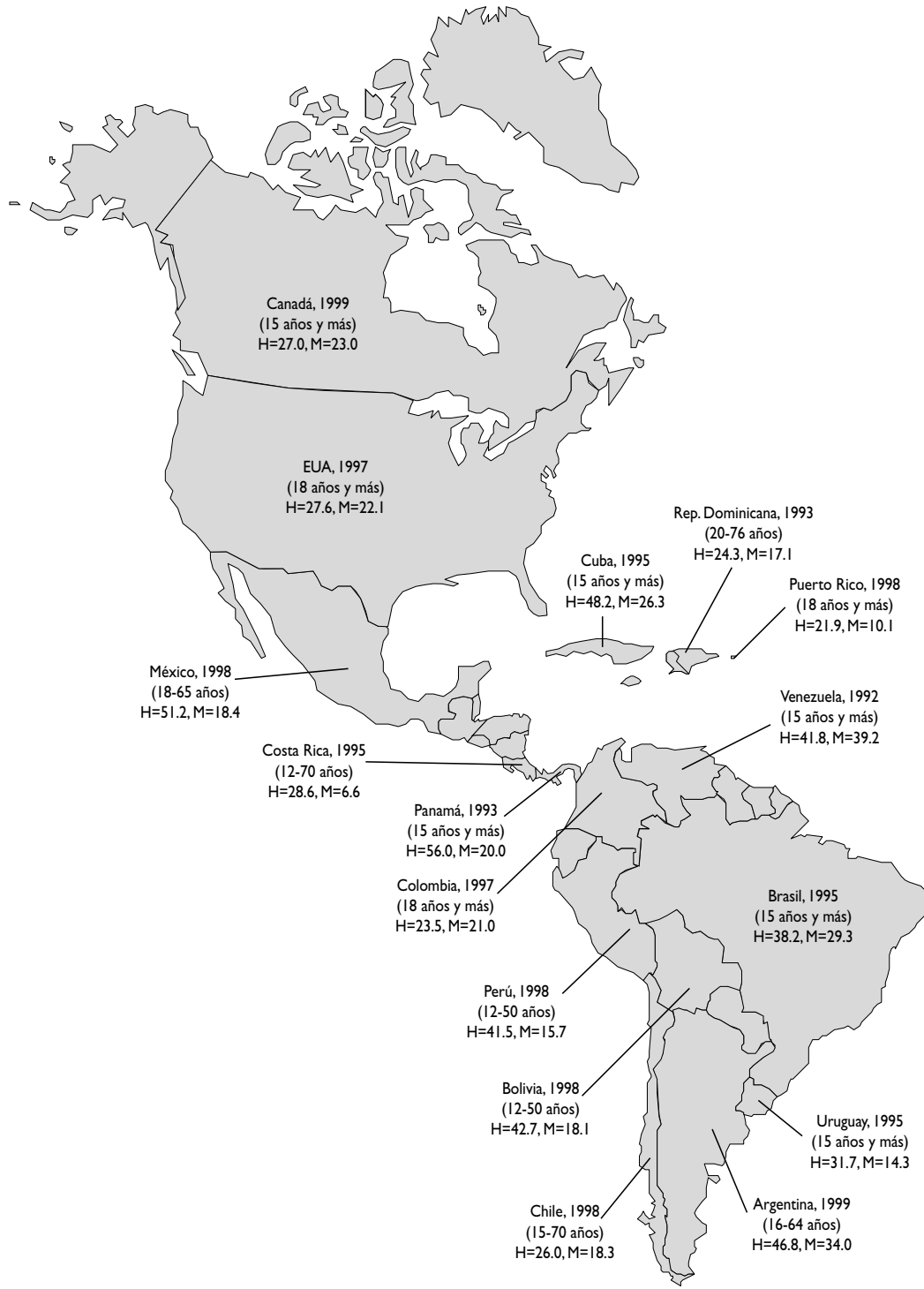

Fuente: Corrao MA, Guindon GE, Sharman N, Shokoohi DF, ed. Tobacco control country profiles. Atlanta (GA): American Cancer Society, 2000

Figura I. Prevalencia de consumo de tabaco en la región de las Américas tabacalera se está introduciendo en los países en desarrollo, son los países industrializados los que siguen recibiendo la mayor atención y los recursos para investigación, cabildeo y acciones para el control del tabaquismo.

Entre los resultados en que coincidieron ampliamente los delegados se encuentra el alza en la prevalencia de mujeres fumadoras y las altas tasas de incremento en el consumo en los menores de 18 años. De lo anterior, se concluye que actualmente no sólo fuma una mayor cantidad de jóvenes sino que se inician en el consumo desde edades cada vez más tempranas.

Este evento mundial dejó una experiencia que le permitirá a cada país participante organizar mejor su infraestructura y estrategias, así como coordinar los esfuerzos necesarios para avanzar en el combate a la epidemia del tabaquismo. También, se espera fortalecer los vínculos institucionales de manera tal que se establezcan verdaderas redes de trabajo involucradas en la prevención y el tratamiento del consumo de tabaco, así como en la lucha por lograr una mayor regulación en el ámbito legislativo que apoye las acciones de protección a la salud y se promuevan los espacios libres de humo.

En la medida en que se den pasos concretos en este sentido, se habrá avanzado ciertamente en los tres temas centrales que se abordaron en esta reunión y se podrá llegar con más optimismo a la XII Conferencia Mundial sobre Tabaco o Salud, a celebrarse en la ciudad de Estambul el año 2003.

M. en C. Raydel Valdés Salgado, Ph. D. Mauricio Hernández Avila, Centro de Investigación en Salud Poblacional, Instituto Nacional de Salud Pública, México. Correo electrónico: rayvs@insp3.insp.mx 